\title{
Efficacy and safety of post-cesarean section incisional infiltration with lidocaine and epinephrine versus lidocaine alone in reducing postoperative pain: A randomized controlled double-blinded clinical trial
}

\author{
Ahmed A. Tharwat ${ }^{1}$, Amr H. Yehia ${ }^{1}$, Karim A. Wahba ${ }^{1}$, Abd-Elrhman G. Ali ${ }^{2}$ \\ ${ }^{1}$ Department of Obstetrics and Gynecology, Ain Shams University Maternity Hospital, Cairo, Egypt \\ ${ }^{2}$ Department of Obstetrics and Gynecology, Misr Al-Gededa Military Hospital, Cairo, Egypt
}

\section{Abstract}

Objective: Aim was to assess the efficacy and safety of incisional infiltration of lidocaine and epinephrine vs. lidocaine only to reduce postcesarean section $(\mathrm{C} / \mathrm{S})$ pain.

Material and Methods: It was a prospective, randomized, controlled, double-blinded clinical trial that was conducted in two tertiary hospitals in Egypt and included 153 women undergoing $\mathrm{C} / \mathrm{S}$ under general anesthesia. They were randomly divided into the following two groups: Group I (control group, number $=78$ ), in which the wound was infiltrated before skin closure with $20 \mathrm{~mL}$ of $2 \%$ lidocaine, and Group II (study group, number=75), in which the wound was infiltrated before skin closure with $20 \mathrm{~mL}$ of $2 \%$ lidocaine and epinephrine. The primary outcomes were the time to first analgesic (TFA) request (minutes) and the postoperative pain scores that were measured using a visual analogue scale (VAS). The secondary outcomes included the duration of $\mathrm{C} / \mathrm{S}$, onset of mobilization, onset of breastfeeding, duration of hospital stay, local or systemic side effects of lidocaine and epinephrine, postoperative pyrexia, and postoperative wound infection.

Results: The pain score determined using VAS after 1 and $2 \mathrm{~h}$ was significantly decreased in Group II than in Group I. However, at 4.8 and $16 \mathrm{~h}$, these results were significantly reversed in Group II than in Group I. The cumulative postoperative opioid consumption was significantly less in Group II than in Group I (50 vs. $90 \mathrm{mg}$ ). The onset of mobilization, onset of breastfeeding, and duration of hospital stay was significantly shorter in Group II than in Group I, whereas the TFA request was significantly longer in Group II.

Conclusion: Administering epinephrine with $2 \%$ lidocaine prolongs the anesthetic effect and reduces the opioid analgesic dose postoperatively required, thereby enhancing patient recovery. (J Turk Ger Gynecol Assoc 2016; 17: 1-5)

Keywords: Local anesthetic, lidocaine, epinephrine, cesarean section

Received: 11 September, $2015 \quad$ Accepted: 12 December, 2015

Available Online Date: 12 January, 2016

\section{Introduction}

With approximately one of three babies surgically born, cesarean section $(\mathrm{C} / \mathrm{S})$ is the most frequent surgery performed worldwide (1). The World Health Organization has advised all healthcare bodies worldwide to maintain the $\mathrm{C} / \mathrm{S}$ rate well under $15 \%$. Nevertheless, recently, the rate has reached up to $46 \%$ in China and well above $25 \%$ in other countries in Asia, Africa, and Latin America and in the United States (2); such an increase might be related to the changes in the physicians' practice patterns, financial incentives, and patients' preferences (3).

Pain is an upsetting feeling that usually delays a patient's recovery and can be accompanied by tissue damage. Proper pain assessment provides crucial information that helps in diagnosing various types of pain, such as somatic, neuropathic, or visceral pain (4).
Unfortunately, to date, postoperative pain is not properly controlled because of many factors. One of these is the inability to efficiently put into action pain management protocols, together with the lack of precision of pain assessment techniques (5). Others factors include wrong beliefs and the patients' high expectations. There is usually a lack in customizing analgesic strategies to satisfy the patients' requirements. Acute pain has detrimental effects if left untreated because it results in acute neurohumoral changes, neuronal re-modeling, depression, anxiety, insomnia, loss of control, inability to sense and communicate with others, and long-lasting psychological and emotional illness and may also end up in prolonged chronic pain states $(6,7)$. In contrast, sufficient control of post-C/S pain is imperative to relieve the patients' discomfort and to enhance breastfeeding performance and infant care (8). 
Usually, high doses of opioid analgesics are necessary to ease severe postoperative pain; however, this strategy has many disadvantages, such as evident disruption of mother-newborn bonding (9). Local anesthesia is of help because of the decreased opioid consumption, and it can be used because of its affordability as part of the smart strategic protocol for pain relief (10).

This study aimed to assess the efficacy and safety of incisional infiltration of lidocaine and epinephrine vs. lidocaine only to reduce post-C/S pain, and thus, enhance the patient's recovery.

\section{Material and Methods}

This was a prospective, randomized, controlled, double-blinded clinical trial that was conducted in two tertiary hospitals in Egypt (Ain Shams University Maternity Hospital and Mis Al-Gededa Military Hospital) in the period from August 2014 to February 2015.

The study was approved by the research ethical committee of Ain Shams University Maternity Hospital in March 2014 according to the World Medical Association Declaration of Helsinki and was registered on clinicalTrails.gov. with the study registration number (NCT 02274974).

A total of 160 women undergoing $\mathrm{C} / \mathrm{S}$ under general anesthesia for various indications were included. Women with known or suspected sensitivity to local anesthesia, medical disorders that were induced by pregnancy as pre-eclampsia, medical disorders aggravated by pregnancy as cardiovascular diseases, hemodynamically unstable patients, or patients lacking adequate verbal communication were excluded. Of 160 women, 153 met the inclusion criteria. All participants signed a written informed consent after the benefits and risks of the trial were explained, and they had the right to withdraw from the study at any time.

The patients were randomly divided into the following two groups: Group I (control group, $n=78$ ), in which the wound was infiltrated before skin closure with $20 \mathrm{~mL}$ of $2 \%$ lidocaine (Arab Drug Company for pharmaceuticals; AL Amireya, Cairo, Egypt), and Group II (study group, $n=75$ ), in which the wound was infiltrated before skin closure with $20 \mathrm{ml}$ of $2 \%$ lidocaine and epinephrine in a dose-related manner, i.e., 1:200,000 [by adding $1 / 4$ of an ampoule of $1 \mathrm{mg} / \mathrm{mL}$ adrenaline (Misr pharmaceutical industries; El Matareya, Cairo, Egypt) to a bottle of lidocaine HCL $2 \% 50 \mathrm{~mL}(20 \mathrm{mg} / \mathrm{mL})]$.

Patients were randomly assigned to either Group I or II using a computer-generated random number list, which was generated using Medcalc ${ }^{\odot}$ version 12.5 (Medcalc Software; Ostend, Belgium). The randomization list was concealed and accessed by sequentially numbered, opaque, sealed envelopes, immediately before the intervention. The patient, surgeon, and personnel involved in the assessment of postoperative pain were blinded to both of the groups. Two identical bottles for masking were prepared, one containing lidocaine only and the other containing lidocaine and epinephrine.

All $\mathrm{C} / \mathrm{S}$ were performed by surgeons with the same level of training and experience (senior registrars). The technique and suture materials used in all cases were the same. The skin was closed by subcuticular sutures using delayed absorbable synthetic suture [vicryl $(2-0)^{\circledR}$ ]. Prior to the infiltration of the solution in both groups, the anesthetist was informed to check for any side effects.

Pain severity was measured using a 10-point visual analogue scale (VAS) at $15 \mathrm{~min}, 1,2,4,8,16$, and $24 \mathrm{~h}$ after recovery from anesthesia. The amount of opioids (pethidine) (Misr pharmaceutical industries; El Matareya, Cairo, Egypt) consumed after $1,2,4,8,16$, and $24 \mathrm{~h}$ was recorded.

The primary outcomes were the time to first analgesic (TFA) request (minutes) and the postoperative pain scores that were measured using VAS. The secondary outcomes included the duration of $\mathrm{C} / \mathrm{S}$ in minutes, onset of mobilization in minutes, onset of breastfeeding in minutes, duration of hospital stay in hours, local and systemic side effects of infiltration of lidocaine and epinephrine, postoperative pyrexia $\left(\geq 38^{\circ} \mathrm{C}\right)$ on two occasions, postoperative wound infection, liver function tests, and renal function tests pre- and postoperatively.

\section{Sample size verification}

The sample size required was estimated using the $G^{*}$ Power software version 3.1.7 (Institute of Experimental Psychology, Heinrich Heine University, Dusseldorf, Germany). A previous study by Fouladi et al. (11) reported that in women receiving postincisional lidocaine alone, the maximum pain scores were observed at 3 and $6 \mathrm{~h}$ postoperation with mean VAS scores \pm standard deviation (SD) of $5.1 \pm(1.4)$ and $5.0 \pm(1.3)$, respectively. According to the same study, the TFA request that was associated with postincisional infiltration of lidocaine was $3.3 \pm(2.0) \mathrm{h}$.

Since there was no previous available data regarding the effect of adding epinephrine to lidocaine for postincisional wound infiltration after $\mathrm{C} / \mathrm{S}$ on postoperative pain and duration of analgesia, the sample size required for this study was estimated on the basis of targeting a standardized effect size, which was considered clinically relevant. Thus, it was estimated that a sample size of 64 patients per group would achieve a power of $80 \%$ (type II error, 0.2 ) to detect a medium effect size (Cohen's $\mathrm{d}=0.5$ ) with regard to the outcome measures. The effect size (d) was calculated as follows: $d=\left(m_{1}-m_{2}\right) / s$, where $m_{1}=$ mean of the control group, $\mathrm{m}_{2}=$ mean of the experimental group, and $\mathrm{s}=$ pooled standard deviation. Seventy patients were included in each group (estimating a 10\% drop out).

The statistical test performed for sample size estimation was the two-sided unpaired t-test, and the type I error was set at a conventional value of 0.05 (confidence level=95\%).

\section{Statistical analysis}

Data were analyzed using IBM $^{\odot}$ SPSS Statistics version 22 (IBM

Corp.; Armonk, New York, USA) and MedCalc ${ }^{\odot}$ version 13 (MedCalc Software; Ostend, Belgium).

Normally distributed numerical variables were interpreted as mean and SD, and intergroup differences were compared using the unpaired student's t-test.

Non-normally distributed numerical variables were presented as median (interquartile range), and between-group differences were compared using the Mann-Whitney test.

Categorical variables were presented as a number and percentage, and the Pearson chi-square test was used to compare 
intergroup differences. Ordinal variables were compared using the chi-square test for trend. $\mathrm{p}$ value of $<0.05$ was considered statistically significant.

\section{Results}

Figure 1 shows the CONSORT flow chart of this study. A total of 160 patients were assessed for their eligibility to participate in the study. Of 160 patients, only 153 were actually randomized to participate in the study. Because of the loss of contact and some other factors, 145 patients actually participated in the study, with 70 patients in Group II and 75 in Group I (the numbers in each group were higher than the anticipated sample size as the anticipated losses were less).

Table 1 shows the demographic data in both groups, and it revealed that both groups were matched with regard to age, weight, height, body mass index, and parity, with no significant difference.

Table 2 shows that the signs of early recovery following $\mathrm{C} / \mathrm{S}$ was highly significantly quicker in Group II than in Group I, as demonstrated by an earlier onset of mobilization $(\mathrm{p}<0.0001)$ and breastfeeding $(\mathrm{p}<0.0001)$ and a shorter duration of hospital stay $(\mathrm{p}<0.0001)$. The duration of $\mathrm{C} / \mathrm{S}$ did not significantly differ between both the groups $(p=0.289)$. The TFA request was significantly longer in Group II than in Group I $(\mathrm{p}<0.0001)$.

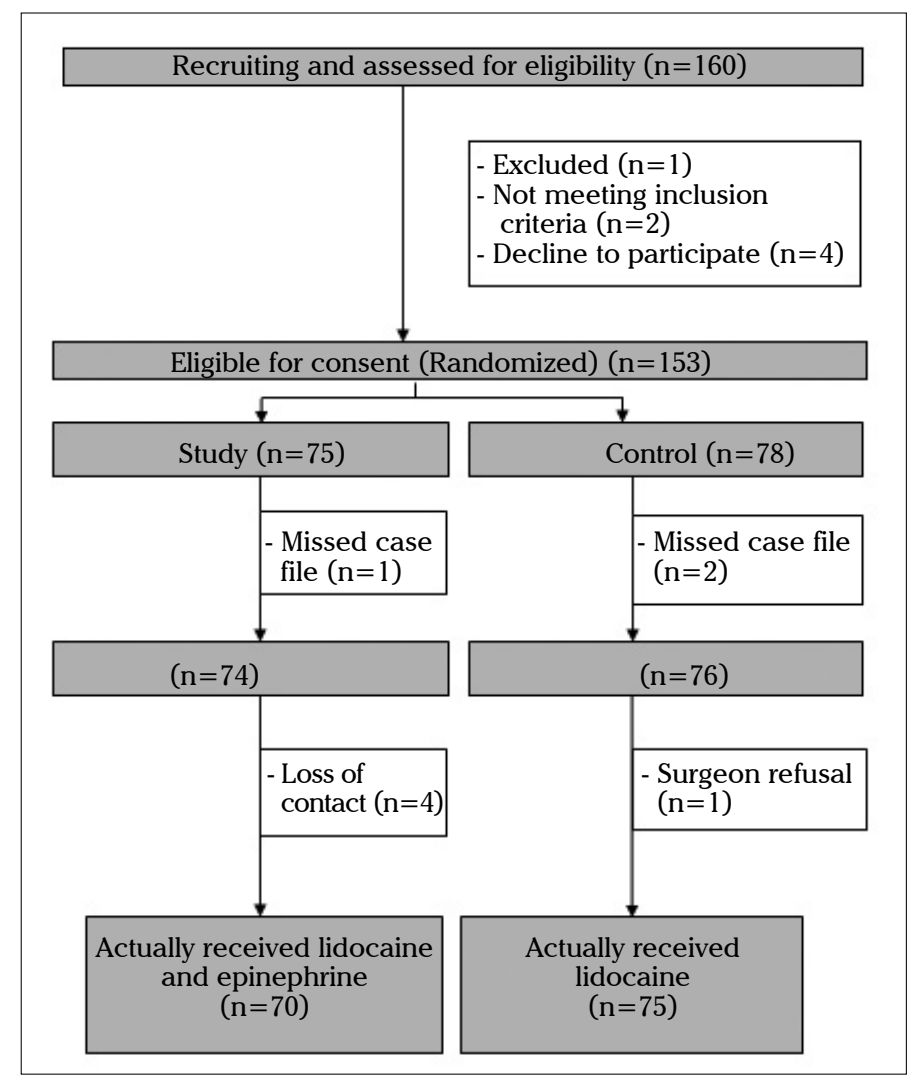

Figure 1. A consort flow chart of both the groups of the study At the beginning of the study, 160 patients were recruited and assessed for eligibility. Of them, only 153 patients were included and randomized in the study (lidocaine-epinephrine) and control (lidocaine only) groups; however, because of various reasons, after dropouts, only 145 patients participated in the study; 70 patients in the study group and 75 in the control group.
Table 3 shows the cumulative postoperative opioid consumption in both the groups, and the consumption was highly significantly less in Group II than in Group I $(p<0.0001)$, which means that administering epinephrine with lidocaine is more effective in postoperative pain control. Furthermore, Table 3 showed a significant decrease in pain score at 1 and $2 \mathrm{~h}$ in Group II than that in Group I $(\mathrm{p}<0.0001)$. These results were significantly reversed at 4 and $16 \mathrm{~h}(\mathrm{p}=0.011$ at $4 \mathrm{~h}, \mathrm{p}=0.028$ at $8 \mathrm{~h}$, and $\mathrm{p}=0.023$ at $16 \mathrm{~h}$ ). At $24 \mathrm{~h}$, there was no significant difference in pain scores between both the groups $(p=0.938)$.

There was no significant difference between both the groups regarding the pre- and postoperative renal and liver functions. There was a significant decrease in the hemoglobin level of $1 \mathrm{~g} /$ $\mathrm{dL}$ and hematocrit value of $3 \%$ in both the groups with respect to the pre- and postoperative results, with no significant difference between both the groups.

In both the groups, none of the patients developed postoperative infection, postoperative pyrexia, allergic reactions, or complications from general anesthesia, local anesthesia, or epinephrine.

\section{Discussion}

$\mathrm{C} / \mathrm{S}$ is the most common laparotomy currently performed worldwide; thus, any useful refinement in the operative technique, however minimal, is likely to yield substantial benefits and cause early recovery $(1,12)$. The surgical technique for cesarean delivery has changed from time to time and surgeon to surgeon, and these changes involved both the uterine and skin incisions (12). A major objective in $\mathrm{C} / \mathrm{S}$ is to attempt to reduce the postoperative pain, and thus, enhance the maternal recovery. This will have an immense effect on the neonate. This was a pilot study (a prospective, randomized, controlled clinical trial) that compared the efficacy and safety of incisional infiltration of lidocaine only vs. lidocaine and epinephrine in reducing post-C/S pain.

Lidocaine and epinephrine combined was more effective than lidocaine only in controlling post-C/S pain as shown by the decrease in the pain score using VAS $=1$ vs. 3 after $1 \mathrm{~h}$ and VAS $=3$ vs. 7 after $2 \mathrm{~h}$ in Group II vs. Group I, respectively. However, these results were reversed at 4.8 and $16 \mathrm{~h}(\mathrm{VAS}=7$ vs. 6,6 vs. 5,4 vs. 3 ) in Group II vs. Group I.

The earlier requirement for administration and the significantly higher amount of consumption of pethidine during the first 24 $\mathrm{h}$ in Group I compared with those in Group II indicated that administering epinephrine with lidocaine in Group II helped in reducing pain; however, at the same time, higher pethidine doses participated in improving the degree of pain control in Group I compared with Group II at 4, 8, and $16 \mathrm{~h}$. After $24 \mathrm{~h}$, both the groups had the same degree of pain according to VAS. There was an earlier onset of lactation in Group II than in Group I, with a difference of $43 \mathrm{~min}$. Mobilization was earlier in Group I, with a difference of 45 min. Patients in Group II had a shorter duration of hospital stay, and $97.1 \%$ of women in Group II stayed for $24 \mathrm{~h}$ compared with $62.7 \%$ in the control. None of the patients in Group II stayed for $36 \mathrm{~h}$ compared with 14.7\% of patients in Group I; only $2.9 \%$ of patients stayed for $48 \mathrm{~h}$ in Group II compared with $22.7 \%$ in Group I. 
Table 1. Patients' demographic data in both the groups

\begin{tabular}{|c|c|c|c|c|}
\hline Variable & $\begin{array}{c}\begin{array}{c}\text { Control group } \\
(\text { number }=75)\end{array} \\
\text { Mean (SD) }\end{array}$ & $\begin{array}{c}\begin{array}{c}\text { Study group } \\
(\text { number }=70)\end{array} \\
\text { Mean (SD) }\end{array}$ & $\mathbf{p}$ & Significance \\
\hline Age (years) & $28.3(4.4)$ & $28.0(4.8)$ & $0.731^{*}$ & NS \\
\hline Weight (kg) & $78.4(5.1)$ & $76.8(6.1)$ & $0.087^{*}$ & NS \\
\hline Height $(\mathrm{cm})$ & $166.8(5.8)$ & $168.0(4.3)$ & $0.161 *$ & NS \\
\hline BMI $\left(\mathrm{kg} / \mathrm{m}^{2}\right)$ & $28.2(3.8)$ & $27.3(2.9)$ & $0.113^{*}$ & NS \\
\hline Parity & Number (\%) & Number (\%) & & \\
\hline $\mathrm{P} 0$ & $30(40.0 \%)$ & $25(35.7 \%)$ & \multirow{5}{*}{$0.474 * *$} & \multirow{5}{*}{ NS } \\
\hline $\mathrm{P} 1$ & $15(20.0 \%)$ & $13(18.6 \%)$ & & \\
\hline $\mathrm{P} 2$ & $20(26.7 \%)$ & $22(31.4 \%)$ & & \\
\hline P3 & $8(10.7 \%)$ & $6(8.6 \%)$ & & \\
\hline P4 & $2(2.7 \%)$ & $4(5.7 \%)$ & & \\
\hline
\end{tabular}

SD: standard deviation; NS: non-significant; BMI: body mass index; P: parity *Analytical test used is independent student's t-test.

**Analytical test used is Chi-square $\left(\chi^{2}\right)$ test.

Table 2. Duration of cesarean section, time to first analgesic request, time of onset of mobilization, time of onset of breastfeeding, and duration of hospital stay in both the groups

\begin{tabular}{|c|c|c|c|c|}
\hline Variable & $\begin{array}{c}\text { Control group } \\
\text { (number=75) } \\
\text { Mean (SD) }\end{array}$ & $\begin{array}{l}\text { Study group } \\
\text { (number=70) } \\
\text { Mean (SD) }\end{array}$ & $\mathbf{p}$ & Significance \\
\hline $\begin{array}{l}\text { Duration of } \\
\mathrm{C} / \mathrm{S} \text { (minutes) }\end{array}$ & $43.13(10.77)$ & $46.42(24.37)$ & $0.289 *$ & NS \\
\hline $\begin{array}{l}\text { Time to first } \\
\text { analgesic } \\
\text { request } \\
\text { (minutes) }\end{array}$ & 87.57 (41.7) & $122.33(56.8)$ & $<0.0001^{*}$ & HS \\
\hline $\begin{array}{l}\text { Time of onset } \\
\text { of mobilization } \\
\text { (minutes) }\end{array}$ & $127.53(72.33)$ & 82.57 (26.14) & $<0.0001^{*}$ & HS \\
\hline $\begin{array}{l}\text { Time of } \\
\text { onset of } \\
\text { breastfeeding } \\
\text { (minutes) }\end{array}$ & $132.13(58.04)$ & $89.42(25.47)$ & $<0.0001^{*}$ & HS \\
\hline Duration of & $31.8(10.6)$ & $22.4(4.8)$ & $<0.0001^{*}$ & $\mathrm{HS}$ \\
\hline & Number (\%) & Number (\%) & & \\
\hline $24 \mathrm{~h}$ & $47(62.7)$ & $68(97.1)$ & \multirow{3}{*}{$<0.0001^{* *}$} & \multirow{3}{*}{$\mathrm{HS}$} \\
\hline $36 \mathrm{~h}$ & $11(14.7)$ & $0(0.0)$ & & \\
\hline $48 \mathrm{~h}$ & $17(22.7)$ & $2(2.9)$ & & \\
\hline \multicolumn{5}{|c|}{$\begin{array}{l}\text { SD: standard deviation; CS: cesarean section; NS: non-significant; HS: highly significant } \\
\text { *Analytical test used is independent student's t-test. } \\
\text { **Analytical test used is Chi-square }\left(\chi^{2}\right) \text { test. }\end{array}$} \\
\hline
\end{tabular}

Many studies in the literature focused on injecting local anesthetic at the incision site to reduce postoperative pain and enhance recovery, but none concentrated on the role of adding epinephrine to the local anesthetic. In a study assessing
Table 3. Postoperative pain scores and cumulative opioid (pethidine) consumption in both the groups

\begin{tabular}{|l|c|c|c|c|}
\hline Variable & $\begin{array}{c}\text { Control group } \\
\text { (number=75) } \\
\text { Mean (SD) }\end{array}$ & $\begin{array}{c}\text { Study group } \\
\text { (number=70) } \\
\text { Mean (SD) }\end{array}$ & p & Significance \\
\hline $\begin{array}{l}\text { VAS score } \\
\text { at 15 min }\end{array}$ & $0(0-1)$ & $0(0-1)$ & $>0.05^{*}$ & NS \\
\hline $\begin{array}{l}\text { VAS score } \\
\text { at 1 h }\end{array}$ & $3(2-7)$ & $1(0-1)$ & $<0.0001^{*}$ & HS \\
\hline $\begin{array}{l}\text { VAS score } \\
\text { at 2 h }\end{array}$ & $7(6-8)$ & $2(1-5)$ & $<0.0001^{*}$ & HS \\
\hline $\begin{array}{l}\text { VAS score } \\
\text { at } 4 h\end{array}$ & $6(6-7)$ & $7(6-8)$ & $0.011^{*}$ & S \\
\hline $\begin{array}{l}\text { VAS score } \\
\text { at } 8 \text { h }\end{array}$ & $5(4-6)$ & $6(5-7)$ & $0.028^{*}$ & S \\
\hline $\begin{array}{l}\text { VAS score } \\
\text { at 16 h }\end{array}$ & $3(2-5)$ & $4(3-5)$ & $0.023^{*}$ & S \\
\hline $\begin{array}{l}\text { VAS score } \\
\text { at 24 h }\end{array}$ & $1(0-2)$ & $1(0-2)$ & $0.938^{*}$ & NS \\
\hline $\begin{array}{l}\text { Cumulative } \\
\text { opioid } \\
\text { (pethidine) } \\
\text { consumption } \\
\text { (mg) }\end{array}$ & 90 (80-100) & 50 (40-70) & $<0.0001^{*}$ & HS \\
\hline $\begin{array}{l}\text { SD: standard deviation; VAS: visual analogue scale for pain; NS: non- } \\
\text { significant; S: significant; HS: highly significant } \\
* \text { Analytical test used is the Mann-Whitney test. }\end{array}$ & \\
\hline
\end{tabular}

the maternal and fetal outcomes of local wound infiltration with lidocaine alone either preincisionally, postincisionally or combined in elective $\mathrm{C} / \mathrm{S}$, it showed that combined pre- and postincisional local wound infiltration is superior to each one alone in pain relief (11).

A Cochrane database review in 2009 that included 20 studies demonstrated that regional and general anesthesia if combined with local analgesia infiltration and abdominal nerve blocks could be of major benefit in $\mathrm{C} / \mathrm{S}$ aiming to minimize the use of opioids. Non-steroidal anti-inflammatory drugs may also offer additional pain control (13).

Tumescent anesthesia, which is injecting a very dilute solution of local anesthetic combined with epinephrine and sodium bicarbonate into tissue until it becomes firm and tense, has been widely preoperatively used in many surgical applications, such as liposuction; vascular surgery; breast surgery; plastic surgery; and ear, nose, and throat procedures (14). It reduces blood loss through epinephrine-induced vasoconstriction and hydrostatic compression from the tumescent effect. Sodium bicarbonate minimizes pain occurring from the injection of an acidic local anesthetic solution. Lidocaine is very slowly absorbed from the subcutaneous tissues producing lower and a more delayed peak blood levels compared with other routes, thereby extending the postoperative duration of analgesia. Slow systemic absorption enables rapid hepatic plasma clearance of lidocaine to maintain safe local anesthetic blood levels (15). 
Previous trials regarding the use of the combination of lidocaine and epinephrine were related to the ear and nose surgery as in Häfner et al. (16), which demonstrated that epinephrine prolonged the duration of action of lidocaine with a decrease in pain degree without any complications.

Another study of local anesthesia using buffered $0.5 \%$ lidocaine with 1:200,000 epinephrine for surgical excision of tumors of the digits by Firoz et al. (17) concluded that epinephrine prolonged the duration of action of lidocaine with a decrease in pain perception without any ischemic complication for the digits.

The following are some limitations of this study:

1) Small sample size. We will require further studies on larger numbers of patients to confirm the results.

2) This study did not include obese pregnant patients with body mass index of $>35$ and patients receiving regional anesthesia.

3) This study did not compare pre- vs. postincisional or combined injection of lidocaine and epinephrine in reducing post-C/S pain.

We conclude from this study that administering epinephrine with local anesthetics (such as $2 \%$ lidocaine in a dose-related manner, 1:200,000) prolongs its anesthetic effect and reduces the opioid analgesic dose postoperatively required. This enables early onset of mobilization and breastfeeding and shorter duration of hospital stay with no systemic or local complications.

Ethics Committee Approval: Ethics committee approval was received for this study from the ethics committee of Ain Shams University Maternity hospital.

Informed Consent: Written informed consent was obtained from patients who participated in this study.

Peer-review: Externally peer-reviewed.

Author Contributions: Concept - A.T., A.A.; Design - A.Y., K.W.; Supervision - A.T., A.Y.; Materials - A.A., A.Y., K.W.; Data Collection and/or Processing A.A., K.W.; Analysis and/or Interpretation - K.W.; Literature Review - A.A, K.W., A.Y.; Writer - K.W., A.A.; Critical Review - A.T., A.Y.;

Acknowledgements: Authors are grateful to all women who agreed to participate in this study.

Conflict of Interest: No conflict of interest was declared by the authors.

Financial Disclosure: The authors declared that this study has received no financial support.

\section{References}

1. Menacker F, Declereq E, Macdorman MF. Cesarean delivery: background, trends and epidemiology. Semin Perinatol 2006; 30: 235-41 [CrossRef].
2. Cavallaro FL, Cresswell JA, França GV, Victora CG, Barros AJ, Ronsmans C. Trends in cesarean delivery by country and wealth quintile: cross-sectional surveys in southern Asia and sub-Saharan Africa. Bull World Health Organ 2013; 91: 914-22. [CrossRef]

3. Khawaja M, Jurdi R, Kabakian T. Rising trends in cesarean section rates in Egypt. Birth 2004; 31: 12-6. [CrossRef]

4. Ballantyne JC, Mao J. Opioid therapy for chronic pain. N Engl J Med 2003; 349: 1943-53. [CrossRef]

5. Schoenwald A, Clark CR. Acute pain in surgical patients. Contemp Nurse 2006; 22: 97-108. [CrossRef]

6. Coll AM, Ameen JR, Mead D. Postoperative pain assessment tools in day surgery: literature review. J Adv Nurs 2004; 46: 124-33. [CrossRef]

7. Cousins MJ, Brennan F, Carr DB. Pain relief: A universal human right. Pain 2004; 112: 1-4. [CrossRef]

8. Woods AB, Crist B, Kowalewski S, Carroll J, Warren J, Robertson J. A cross-sectional analysis of the effect of patient-controlled epidural analgesia versus patient controlled analgesia on post-cesarean pain and breastfeeding. J Obstet Gynecol Neonatal Nurs 2012; 41: 339-46. [CrossRef]

9. Sakalidis VS, Williams TM, Hepworth AR, Garbin CP, Hartmann $\mathrm{PE}$, Paech MJ, et al. A comparison of early sucking dynamics during breastfeeding after cesarean section and vaginal birth. Breastfeeding Med 2013; 8: 79-85. [CrossRef]

10. Bamigboye AA, Hofmeyr GJ. Cesarean section wound infiltration with local anesthesia for postoperative pain relief - any benefit? $\mathrm{S}$ Afr Med J 2010; 100: 313-9.

11. Fouladi RF, Navali N, Abbassi A. Pre-incisional, post-incisional and combined pre- and post-incisional local wound infiltration with lidocaine in elective cesarean section delivery: A randomized clinical trial. J Obstet Gynaecol 2013; 33: 54-9. [CrossRef]

12. Dandolu V, Raj J, Harmanli O, Lorico A, Chatwani AJ. Resident education regarding technical aspects of cesarean section. J Reprod Med 2006; 51: 49-54.

13. Bamigboye AA, Hofmeyr GJ. Local anesthetic wound infiltration and abdominal nerves block during cesarean section for postoperative pain relief. Cochrane Database Syst Rev 2009; 3: CD006954.

14. Do DV, Kelley LC. Tumescent anesthesia: evolution and current uses. Adv Dermatol 2007; 23: 33-46. [CrossRef]

15. Conroy PH, O'Rourke J. Tumescent anesthesia. Surgeon 2013; 11: 210-21. [CrossRef]

16. Häfner HM, Röcken M, Breuninger H. Epinephrine-supplemented local anesthetics for ear and nose surgery: clinical use without complications in more than 10,000 surgical procedures. J Dtsch Dermatol Ges 2005; 3: 195-9. [CrossRef]

17. Firoz B, Davis N, Goldberg LH. Local anesthesia using buffered 0.5\% lidocaine with 1:200,000 epinephrine for tumors of the digits treated with Mohs micrographic surgery. J Am Acad Dermatol 2009; 61: 639-43. [CrossRef] 